\title{
Florida Rules for Direct Supervision of Unlicensed Pesticide Applicators ${ }^{1}$
}

\author{
Brett W. Bultemeier and Erin E. Harlow ${ }^{2}$
}

The United States Environmental Protection Agency (EPA) classifies pesticides into two large categories: General Use Products (GUP) and Restricted Use Products (RUP). General Use Products can be purchased and used by anyone, whereas Restricted Use Products can only be purchased by those who have a pesticide license. Each state can limit the use of products, RUP or GUP, depending on where and how they are utilized. In many cases, an individual can still use an RUP product if they are under the guidance and supervision of someone who is licensed. But the question remains, what does it mean to be supervised when using RUPs?

The Florida Department of Agriculture and Consumer Services (FDACS) divides pesticide applications into three statutory chapters: 388 (Mosquito Control), 482 (Structural Pest Control), 487 (Agriculture and other sites). For chapters 388 and 487, anyone can use a GUP product without a license or direct supervision requirements. The use of RUPs will always require someone with a license to purchase and a licensed applicator to serve for direct supervision for any unlicensed applicators. Chapter 482 is more restrictive because it regulates pesticide application in and around homes and other occupied buildings. Therefore, 482 applications require anyone without a license to be supervised, regardless of what type of pesticide is used.

This publication will review and describe the direct supervision requirements for all three Florida statutes. It will also provide specifics on direct supervision for licenses that may be more complicated. In Florida, licensed applicators can use RUPs unless additional restrictions apply.

\section{Chapter 388, Mosquito and Public Health Pest Control}

A licensed applicator in Public Health may oversee 10 unlicensed applicators.

The licensed applicator must provide training to unlicensed applicators on the following topics:

- Safety and precautions for each product used

- Personal Protective Equipment (PPE) training

- Common symptoms of pesticide poisoning

- Rules against eating, drinking, and smoking while applying pesticides

- Need to wash clothing and bathe after pesticide applications

- How to reach a nearby medical facility

- How to operate equipment in residential areas to minimize exposure to public

- Emergency spill procedures, particularly after crash of car or airplane

1. This document is PI293, one of a series of the Pesticide Information Office, UF/IFAS Extension. Original publication date August 2021. Visit the EDIS website at https://edis.ifas.ufl.edu for the currently supported version of this publication.

2. Brett W. Bultemeier, Extension assistant professor, UF/IFAS Pesticide Information Office; and Erin E. Harlow, residential and commercial horticulture agent III, UF/IFAS Extension Columbia County; UF/IFAS Extension, Gainesville, FL 32611.

The Institute of Food and Agricultural Sciences (IFAS) is an Equal Opportunity Institution authorized to provide research, educational information and other services

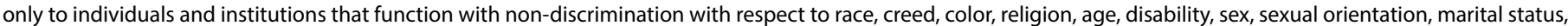

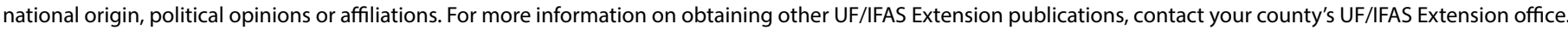
U.S. Department of Agriculture, UF/IFAS Extension Service, University of Florida, IFAS, Florida A \& M University Cooperative Extension Program, and Boards of County Commissioners Cooperating. Nick T. Place, dean for UF/IFAS Extension. 
- Requirements to keep training records and make them available for 3 years

\section{Chapter 487, RUP/Agricultural License}

A licensed applicator may oversee 15 unlicensed applicators using RUP products.

The licensed applicator must:

- Be available by phone at all times.

- Be able to get to the site of application before or during pesticide use.

- Train users in:

- Safety and precautions for each product used.

- PPE training.

- Common signs of pesticide poisoning.

- Rules against eating, drinking, and smoking while applying pesticides.

- The need to wash clothing and bathe after pesticide applications.

- How to reach a nearby medical facility.

- How and under what circumstances to contact the licensed applicator who serves as direct supervisor.

The above training requirements would not apply to agricultural production, such as farms, nurseries, forests, etc. These locations have more specific rules that fall under the Worker Protection Standard (WPS).

\section{Chapter 482, Structural Pest Control}

Only Certified Pest Control Operators (also called Pest Control Operators) (CPO or PCO) may supervise unlicensed individuals. Although any $\mathrm{CPO}$ or PCO can supervise unlicensed applicators, each location or "branch" must have a designated $\mathrm{PCO} / \mathrm{CPO}$ in charge. This individual will have their name associated with the business license for that location. There is no limit on how many unlicensed applicators can be under direct supervision, but they must reside in the same branch/location as the $\mathrm{PCO} / \mathrm{CPO}$ in charge. Individuals that hold certification in "limited" categories (such as Limited Commercial Landscape Maintenance and others) are not allowed to directly supervise anyone. While limited license holders cannot supervise others, they can still use RUPs unless the license restricts it.
The PCO/CPO in charge must:

- Be available by phone at all times for direction and guidance during treatments.

- Be able to get to the treatment site before or during any pesticide application.

- Maintain training records for 2 years.

- Consult unlicensed employees regarding:

- Chemical selection.

- Safe and proper pesticide use.

- Proper concentrations for formulations of pesticide used.

\section{Supervised Unlicensed Employee (ID Cardholder)}

Each supervised unlicensed employee (ID Cardholder) must:

- Complete 40 hours of site training under supervision, direction and control of the $\mathrm{PCO} / \mathrm{CPO}$ incharge prior to performing, soliciting, inspecting or applying pest control.

- Complete 4 continuing education units (CEUs) within 6 months of receiving ID card.

- CEUs must cover pesticide safety, integrated pest management, and federal and state laws.

- CEUs from FDACS-approved providers will work, and so will technician training hours provided by the $\mathrm{PCO} / \mathrm{CPO}$ in charge.

- Earn 2 CEUs concerning the same criteria as above every year thereafter.

\section{Wood-Destroying Organisms (WDO)}

In addition to the steps listed under Supervised Unlicensed Employee, those seeking to do inspections for Wood-Destroying Organisms (WDO) must attain a Special ID card. To attain this Special ID card the employee must additionally be trained by the $\mathrm{PCO} / \mathrm{CPO}$ in charge in the following:

- Detection and control of wood-destroying organisms

- Biology, behavior, and identification of WDO

- Inspection forms to be used for reporting

- Applicable federal, state, and local laws 


\section{Fumigation}

In addition to the steps listed under Supervised Unlicensed Employee, those seeking to serve as the secondary person on fumigations, but not as the primary person, must attain a Fumigation Identification Card Endorsement (FID). To attain this FID endorsement the employee must additionally be trained by the $\mathrm{PCO} / \mathrm{CPO}$ in charge in the following:

- Basic fumigation procedures

- SCBA (self-contained breathing apparatus) use

- Proper use of fumigant safety equipment

- Immediate reporting of any irregularities or emergencies to the certified operator in charge or his/her special fumigation identification cardholder (SPID)

In addition to the steps listed under Supervised Unlicensed Employee, those seeking to serve as the primary person in fumigations must additionally:

- Pass the Special ID Cardholder in Fumigation exam (SPID).

- Still work under direct supervision of a PCO/CPO in charge.

- For residential fumigation employees, complete Stewardship Training annually.

- To renew ID card, earn 2 CEUs on legislation, safety, and pesticide labeling (CORE) +2 CEUs in fumigation within 6 months and 2 FUM annually thereafter.

- Renewal can also be achieved by passing the Special ID cardholder exam.

For more information on the different statutes or to find which pesticide license an individual might need, reference:

Chapter 388-Mosquito and Public Health Pest Control http://www.leg.state.fl.us/statutes/index.cfm?App_ mode=Display_Statute\&URL=0300-0399/0388/0388.html

Chapter 482-Structural Pest Control http://www.leg. state.fl.us/statutes/index.cfm? App_mode=Display_ Statute\&URL=0400-0499/0482/0482.html

Chapter 487-Restricted Use Pesticides/Agricultural http:// www.leg.state.fl.us/statutes/index.cfm?App_mode=Display_ Statute\&URL=0400-0499/0487/0487.html

\section{What license do I need?}

Harlow, E. E., L. B. Harlow, S. Haddock, and B. Bultemeier. 2021. "Finding the Correct Pesticide Applicator License in Florida." EDIS 2021 (3). https://doi.org/10.32473/ edis-PI292-2021 